\title{
Article \\ The Impact of COVID-19 on the Profile of Hospital-Acquired Infections in Adult Intensive Care Units
}

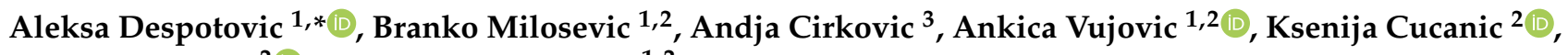 \\ Teodora Cucanic ${ }^{2}$ D and Goran Stevanovic ${ }^{1,2}$ \\ 1 Faculty of Medicine, University of Belgrade, 11000 Belgrade, Serbia; b.milosevic@yahoo.com (B.M.); \\ ankica.vujovic88@gmail.com (A.V.); goran_drste@yahoo.com (G.S.) \\ 2 Teaching Hospital for Infectious and Tropical Diseases, University Clinical Center of Serbia, \\ 11000 Belgrade, Serbia; xeniac995@gmail.com (K.C.); teodorac995@gmail.com (T.C.) \\ 3 Department of Medical Statistics, Faculty of Medicine, University of Belgrade, 11000 Belgrade, Serbia; \\ andja.cirkovic@mfub.bg.ac.rs \\ * Correspondence: alexadespotovic21@gmail.com
}

check for updates

Citation: Despotovic, A.; Milosevic, B.; Cirkovic, A.; Vujovic, A.; Cucanic, K.; Cucanic, T.; Stevanovic, G. The Impact of COVID-19 on the Profile of Hospital-Acquired Infections in Adult Intensive Care Units. Antibiotics 2021, 10, 1146. https://doi.org/10.3390/ antibiotics10101146

Academic Editor: Maria Bagattini

Received: 26 August 2021

Accepted: 17 September 2021

Published: 23 September 2021

Publisher's Note: MDPI stays neutral with regard to jurisdictional claims in published maps and institutional affiliations.

Copyright: (c) 2021 by the authors. Licensee MDPI, Basel, Switzerland. This article is an open access article distributed under the terms and conditions of the Creative Commons Attribution (CC BY) license (https:// creativecommons.org/licenses/by/ $4.0 /)$.

\begin{abstract}
Hospital-acquired infections (HAIs) are a global public health concern. As the COVID19 pandemic continues, its contribution to mortality and antimicrobial resistance (AMR) grows, particularly in intensive care units (ICUs). A two-year retrospective study from April 2019-April 2021 was conducted in an adult ICU at the Hospital for Infectious and Tropical Diseases, Belgrade, Serbia to assess causative agents of HAIs and AMR rates, with the COVID-19 pandemic ensuing halfway through the study. Resistance rates $>80 \%$ were observed for the majority of tested antimicrobials. In COVID-19 patients, Acinetobacter spp. was the dominant cause of HAIs and more frequently isolated than in non-COVID-19 patients. (67 vs. 18, $p=0.001$ ). Also, resistance was higher for imipenem $(56.8 \%$ vs. $24.5 \%, p<0.001)$, meropenem $(61.1 \%$ vs. $24.3 \%, p<0.001)$ and ciprofloxacin $(59.5 \%$ vs. $36.9 \%, p=0.04)$. AMR rates were aggregated with findings from our previous study to identify resistance trends and establish empiric treatment recommendations. The increased presence of Acinetobacter spp. and a positive trend in Klebsiella spp. resistance to fluoroquinolones $\left(\mathrm{R}^{2}=0.980\right.$, $p=0.01)$ and carbapenems $\left(\mathrm{R}^{2}=0.963, p=0.02\right)$ could have contributed to alarming resistance rates across bloodstream infections (BSIs), pneumonia (PN), and urinary tract infections (UTIs). Exceptions were vancomycin $(16.0 \%)$ and linezolid $(2.6 \%)$ in BSIs; tigecycline $(14.3 \%)$ and colistin $(0 \%)$ in PNs; and colistin $(12.0 \%)$ and linezolid $(0 \%)$ in UTIs. COVID-19 has changed the landscape of HAIs in our ICUs. Approval of new drugs and rigorous surveillance is urgently needed.
\end{abstract}

Keywords: hospital-acquired infections; COVID-19; intensive care unit; adults; antimicrobial resistance; empiric therapy; carbapenem resistance; trend analysis; surveillance; Serbia

\section{Introduction}

The burden of hospital-acquired infections (HAIs) on healthcare systems and patients is substantial and constantly growing. Recent surveys show that up to 4.5 million individuals suffer from at least one HAI in acute care hospitals across Europe every year [1-3]. Appropriate infection prevention and control has been particularly challenging since the start of the COVID-19 pandemic, during which studies are showing an increase in HAI occurrence [4-6]. Prior to the pandemic, evidence suggested that up to 55\% of HAIs could be prevented through effective preventative practices [7]. During the pandemic, however, the sudden and enormous demands on healthcare systems has inevitably reduced the quality of infection control worldwide. Furthermore, the use of large amounts of antibiotics and immunosuppressive therapy in COVID-19 patients has only accentuated the problem of antimicrobial resistance (AMR) and the incidence of multidrug-resistant (MDR) organisms $[8,9]$. 
AMR is of particular concern in intensive care units (ICUs), where choices for empiric therapy are limited. Pathogens such as carbapenem-resistant Enterobacteriaceae (CRE) and carbapenem-resistant Acinetobacter baumannii ( $C R A)$ have become hard to treat as carbapenems, the mainstay of both empiric and targeted therapy, are increasingly not fit for use [10]. This has become even more important during the pandemic, as outbreaks of both CRE and CRA are increasingly reported worldwide [11-14], affecting patient outcomes that are already compromised due to COVID-19. Because of these challenges, rigorous local surveillance is critical, as it enables continuous revisions of empiric therapy guidelines and improvement in antimicrobial stewardship, both for initiation of therapy and its de-escalation $[15,16]$.

In Serbia, AMR for HAIs has been evaluated through national point prevalence surveys and isolated reports from various hospitals [17-19], but no studies detailing the profile of HAIs and AMR have been published since the beginning of the pandemic in our country. In our previous two-year study conducted before the pandemic [20], we identified risk factors for both acquisition and mortality in patients with HAIs in adult ICUs and discovered high resistance rates to most tested antibiotics. In this two-year study, spanning from April 2019-April 2021, we further investigated the profile of pathogens and their susceptibility to antibiotics currently used for treatment. We compared AMR rates of pathogens isolated before the pandemic (1 April 2019-31 March 2020) and during the pandemic (1 April 2020-31 March 2021), with the goal of assessing potential differences in causative agents and their antimicrobial susceptibility rates (ASTs). The primary aim, however, was to establish multi-year trends and assess which drugs can still be used for empiric and/or targeted therapy for most common HAIs in ICUs based on local resistance profiles, with respect to the impact of COVID-19.

\section{Results}

A total of 611 patients were admitted to the ICU of the Teaching Hospital for Infectious and Tropical Diseases in Belgrade, Serbia between April 2019 and April 2021. Before the pandemic, the majority of patients treated at our ICU were those suffering from severe forms of central nervous system (CNS), respiratory, systemic and other infections. Since the beginning of the pandemic, however, our hospital and our ICU serve as one of the leading facilities for treatment of patients with severe COVID-19 in the country.

During the study period, a total of 114 patients suffered from at least one HAI, with their clinical and demographic characteristics shown in Table $1.35 .1 \%$ of patients were female, and the median length of stay (LOS) was 24 days (IQR 23). The principal diagnosis for which patients were treated was COVID-19 infection $(n=73,64.0 \%)$ and comprised the majority of patients (93.6\%) admitted to our ICU during the second year of our study. 58 patients $(50.9 \%)$ were directly admitted to our ICU from our ambulatory center, whereas $56(49.1 \%)$ of patients were transferred from other departments of our hospital and other departments from the University Clinical Center of Serbia. Notable comorbidities included cardiovascular disease $(n=83 ; 73.5 \%)$, diabetes $(n=34 ; 30.1 \%)$ and chronic lung disease $(n$ $=14 ; 12.4 \%$ ). All patients received antibiotics $48 \mathrm{~h}$ before or after admission, most common being cephalosporins $(n=63,55.3 \%)$, vancomycin $(n=42,36.8 \%)$ and carbapenems $(n=38$, $33.3 \%)$.

Table 1. Clinical characteristics of 114 patients who suffered from at least one HAI in our study from April 2019-April 2021.

\begin{tabular}{cc}
\hline Patient Characteristics & $\boldsymbol{n = 1 1 4} \mathbf{( \% )}$ \\
\hline Age & $66.2( \pm 13.6$ years $)$ \\
Length of Stay & $24(\mathrm{IQR} 23)$ \\
Sex (Female) & $40(35.1 \%)$ \\
\hline
\end{tabular}


Table 1. Cont.

\begin{tabular}{|c|c|}
\hline Patient Characteristics & $n=114(\%)$ \\
\hline \multicolumn{2}{|l|}{ Primary Diagnosis } \\
\hline COVID-19 Infection & $73(64.0 \%)$ \\
\hline CNS infection & $18(15.8 \%)$ \\
\hline Other respiratory infections & $6(5.3 \%)$ \\
\hline \multicolumn{2}{|l|}{ Admission to ICU } \\
\hline Directly admitted & $58(50.9 \%)$ \\
\hline Transferred from other departments & $56(49.1 \%)$ \\
\hline \multicolumn{2}{|l|}{ Comorbidities } \\
\hline Cardiovascular Disease & $83(73.5 \%)$ \\
\hline Diabetes & $34(30.1 \%)$ \\
\hline Chronic lung disease & $14(12.4 \%)$ \\
\hline Kidney insufficiency & $7(6.2 \%)$ \\
\hline Hypothyroidism & $6(5.3 \%)$ \\
\hline \multicolumn{2}{|l|}{ Invasive device use } \\
\hline Urinary catheter & $110(96.5 \%)$ \\
\hline Central venous line & $60(54.1 \%)$ \\
\hline Intubation & $101(88.6 \%)$ \\
\hline Mechanical ventilation & $99(86.8 \%)$ \\
\hline Antibiotic use 48 before and after admission & $114(100 \%)$ \\
\hline Penicillins & $11(9.6 \%)$ \\
\hline Cephalosporins & $63(55.3 \%)$ \\
\hline Aminoglycosides & $3(2.6 \%)$ \\
\hline Fluoroquinolones & $20(17.5 \%)$ \\
\hline Carbapenems & $38(33.3 \%)$ \\
\hline Vancomycin & $42(36.8 \%)$ \\
\hline$>1 \mathrm{HAI}$ & $53(46.5 \%)$ \\
\hline Polymicrobial infection & $55(33.7 \%)$ \\
\hline
\end{tabular}

n: number of patients; CNS: central nervous system; ICU: intensive care unit; HAI: hospital-acquired infection; IQR: interquartile range.

More than 1 HAI was identified in 53 (46.5\%) of patients and a third of all HAIs were polymicrobial. Therefore, a total of $163 \mathrm{HAI}$ episodes with 226 isolates were confirmed. The most commonly diagnosed HAIs were bloodstream infections (BSI; $n=69,42.3 \%$ ), pneumonia (PN; $n=63,38.7 \%$ ), and urinary tract infections (UTI; $n=15,9.2 \%$ ). Other HAIs were of the skin and soft-tissue (SST; $n=10,6.1 \%$ ), central nervous system (CNS; $n=4,2.5 \%$ ), and 1 episode of otitis externa (EENT) and vaginitis (REPR) each, respectively. $89 \%$ of both PNs and UTIs were classified as device-associated (intubation/ventilationassociated pneumonia, IAP/VAP; and catheter-associated urinary tract infection; CAUTI, respectively). Bacterial pathogens isolated as causative agents of HAIs during our study period are shown in Table 2. Acinetobacter spp. was the most frequently identified pathogen $(n=85,37.6 \%)$, primarily isolated from the respiratory tract $(n=57,72.2 \%)$. Other isolates included Enterococcus spp., coagulase-negative Staphylococcus (CoNS), Klebsiella spp., and Pseudomonas aeruginosa. 176 pathogens (79.3\%) were classified as MDR. A concomitant Clostridium difficile infection was found in 17 patients (12.5\%).

Table 2. Causative agents of HAIs that underwent AST from 1 April 2019-31 March 2021.

\begin{tabular}{ccccc}
\hline Isolates & $\boldsymbol{n = 2 2 6} \mathbf{( \% )}$ & BSI $(\boldsymbol{n = 9 8 )}$ & PN $(\boldsymbol{n = 7 9 )}$ & UTI $(\boldsymbol{n}=\mathbf{1 9})$ \\
\hline Acinetobacter spp. & $85(37.6)$ & $26(26.5)$ & $57(72.2)$ & $2(10.5)$ \\
Enterococcus spp. & $28(12.4)$ & $11(11.2)$ & $2(2.5)$ & $8(42.1)$ \\
$\begin{array}{c}\text { Coagulase-negative } \\
\text { Staphylococcus }\end{array}$ & $27(11.9)$ & $26(26.5)$ & & \\
$\begin{array}{c}\text { Pseudomonas } \\
\text { aeruginosa }\end{array}$ & $21(9.3)$ & $3(3.1)$ & $11(13.9)$ & $2(10.5)$ \\
Klebsiella spp. & $21(9.3)$ & $7(7.1)$ & $5(6.3)$ & $5(26.3)$ \\
\hline
\end{tabular}


Table 2. Cont.

\begin{tabular}{|c|c|c|c|c|}
\hline Isolates & $n=226(\%)$ & BSI $(n=98)$ & $\mathrm{PN}(n=79)$ & UTI $(n=19)$ \\
\hline Proteus mirabilis & $8(3.5)$ & $1(1.0)$ & & $1(5.3)$ \\
\hline Escherichia coli & $5(2.2)$ & $1(1.0)$ & & $1(5.3)$ \\
\hline $\begin{array}{c}\text { Providencia spp. } \\
\text { Other }\end{array}$ & $5(2.2)$ & $2(2.0)$ & & \\
\hline $\begin{array}{l}\text { Staphylococcal } \\
\text { species }\end{array}$ & $5(2.2)$ & $5(5.1)$ & & \\
\hline Staphylococcus aureus & $4(1.8)$ & $2(2.0)$ & $2(2.5)$ & \\
\hline Diphtheroids & $4(1.8)$ & $3(3.1)$ & $1(1.3)$ & \\
\hline $\begin{array}{l}\text { Stenotrophomonas } \\
\text { maltophilla }\end{array}$ & $4(1.8)$ & $3(3.1)$ & $1(1.3)$ & \\
\hline Corynebacterium spp. & $3(1.3)$ & $3(3.1)$ & & \\
\hline $\begin{array}{l}\text { Achromobacter } \\
\text { xylooxidans }\end{array}$ & $3(1.3)$ & $3(3.1)$ & & \\
\hline Prevotella spp. & $1(0.4)$ & $1(1.0)$ & & \\
\hline Kocuria kristinae & $1(0.4)$ & $1(1.0)$ & & \\
\hline
\end{tabular}

Antimicrobial susceptibility testing (AST) revealed alarming resistance rates to almost all tested antibiotics (Table 3). The highest rates were observed against fluoroquinolones (levofloxacin, 97.4\%; ciprofloxacin, 96.4\%; moxifloxacin, 94.4\%) and cephalosporins (cefotaxime $96.3 \%$, cephalexin $95.8 \%$, ceftriaxone $95.7 \%$, ceftazidime $90.0 \%$ ), with overall rates exceeding $90 \%$ for both groups. Resistance to trimethoprim-sulfamethoxazole (TMPSMX) was $88.8 \%$, whereas resistance of $>80 \%$ was also seen for both aminoglycosides (91.6\% and $80.4 \%$ for gentamicin and amikacin, respectively). With the exception of amoxicillin-clavulanic acid $(75.0 \%)$, resistance rates exceeded $>80 \%$ in all other penicillins (methicillin/oxacillin, $92.3 \%$; piperacillin-tazobactam, $87.8 \%$; ampicillin/amoxicillin, $80.4 \%$ ). Resistance to carbapenems was also high $(85.4 \%$ for meropenem and $81.3 \%$ for imipenem), while resistance to ertapenem, though on a much smaller sample size $(n=23)$ was lower $(47.8 \%)$. Resistance to vancomycin (30.8\%) and tigecycline $(28.6 \%)$ is lower compared to most drugs, while colistin $(7.1 \%)$ and linezolid $(2.7 \%)$ showed the lowest resistance rates.

Table 3. Antimicrobial susceptibility testing results from April 2019-April 2021.

\begin{tabular}{|c|c|c|c|}
\hline Antibiotics (n) & \% Resistance & Antibiotics ( $n$ ) & \% Resistance \\
\hline Penicillins & & Cephalosporins & \\
\hline MET/OXA (39) & $92.3 \%$ & Cephalexin (24) & $95.8 \%$ \\
\hline AMP / AMX (56) & $80.4 \%$ & Cefotaxime (27) & $96.3 \%$ \\
\hline AMX-CL (40) & $75.0 \%$ & Ceftriaxone (46) & $95.7 \%$ \\
\hline PIP-TZ (41) & $87.8 \%$ & Ceftazidime (60) & $90.0 \%$ \\
\hline Total (176) & $83.5 \%$ & Total (157) & $93.6 \%$ \\
\hline Fluoroquinolones & & Carbapenems & \\
\hline Ciprofloxacin (168) & $96.4 \%$ & Imipenem (139) & $81.3 \%$ \\
\hline Levofloxacin (156) & $97.4 \%$ & Meropenem (144) & $85.4 \%$ \\
\hline Moxifloxacin (36) & $94.4 \%$ & Ertapenem (23) & $47.8 \%$ \\
\hline Total (360) & $96.7 \%$ & Total (330) & $74.8 \%$ \\
\hline Aminoglycosides & & Glycopeptides & \\
\hline Gentamicin (166) & $91.6 \%$ & Vancomycin (65) & $30.8 \%$ \\
\hline Amikacin (143) & $80.4 \%$ & Teicoplanin (11) & $63.6 \%$ \\
\hline Total (309) & $86.5 \%$ & Total (76) & $35.6 \%$ \\
\hline Other Antibiotics & & Other Antibiotics & \\
\hline TMP-SMX (134) & $88.8 \%$ & Colistin (127) & $7.1 \%$ \\
\hline Tigecycline (21) & $28.6 \%$ & Linezolid (36) & $2.7 \%$ \\
\hline
\end{tabular}


In addition to overall resistance rates, we investigated any potential difference in pathogens causing HAIs in COVID-19 patients compared to non-COVID-19 patients in the pre-pandemic year (Table 4). An association between the diagnosis of COVID-19 and increased resistance to all carbapenems (imipenem, $56.8 \%$ vs. $24.5 \%, p<0.001$; meropenem, $61.1 \%$ vs. $24.3 \%, p<0.001$; and ertapenem, $26.1 \%$ vs. $21.7 \%, p=0.03$ ) has been observed. Ciprofloxacin was the only other antibiotic in which a statistically significant association was identified ( $59.5 \%$ vs. $36.9 \%, p=0.04)$. We also see an association between increased numbers of PNs and the diagnosis of COVID-19 (48 vs. 15, $p=0.008$ ), but also an inverse association between UTIs and the diagnosis of COVID-19 ( 3 vs. $12, p<0.001$ ). The analysis of pathogen distribution shows an association between Acinetobacter spp. as a causative agent of HAIs and a diagnosis of COVID-19 (67 vs. 18, $p=0.001$ ) and an inverse association of Proteus mirabilis and COVID-19 (2 vs. 6, $p=0.02$ ).

Table 4. Resistance rates, types of infection, and pathogen distribution in COVID-19 vs. non-COVID19 patients.

\begin{tabular}{|c|c|c|c|}
\hline Antibiotics (n) & $\begin{array}{l}\text { COVID-19 } \\
(n=73)\end{array}$ & $\begin{array}{l}\text { Non-COVID-19 } \\
\quad(n=41)\end{array}$ & $p$ \\
\hline MET/OXA (39) & $71.80 \%$ & $20.50 \%$ & 0.16 \\
\hline AMP / AMX (56) & $39.30 \%$ & $41.10 \%$ & 1 \\
\hline AMX_CL (40) & $32.50 \%$ & $42.50 \%$ & 0.71 \\
\hline PIP_TZ (41) & $39.00 \%$ & $48.80 \%$ & 0.38 \\
\hline Cefalexin (24) & $29.20 \%$ & $66.70 \%$ & 1 \\
\hline Cefotaxim (27) & $22.20 \%$ & $74.10 \%$ & 1 \\
\hline Ceftriaxon (46) & $34.80 \%$ & $60.90 \%$ & 0.54 \\
\hline Ceftazidime (60) & $31.70 \%$ & $58.30 \%$ & 0.19 \\
\hline Gentamicin (166) & $57.20 \%$ & $34.30 \%$ & 0.16 \\
\hline Amikacin (143) & $53.80 \%$ & $26.60 \%$ & 0.38 \\
\hline Ciprofloxacin (168) & $59.50 \%$ & $36.90 \%$ & 0.04 \\
\hline Levofloxacin (156) & $62.20 \%$ & $35.30 \%$ & 0.14 \\
\hline Moxifloxacin (36) & $47.20 \%$ & $47.20 \%$ & 0.49 \\
\hline Bactrim (134) & $58.20 \%$ & $30.60 \%$ & 0.78 \\
\hline Imipenem (139) & $56.80 \%$ & $24.50 \%$ & $<0.001$ \\
\hline Meropenem (144) & $61.10 \%$ & $24.30 \%$ & $<0.001$ \\
\hline Ertapenem (23) & $26.10 \%$ & $21.70 \%$ & 0.03 \\
\hline Tigycycline (21) & $9.50 \%$ & $19.00 \%$ & 0.36 \\
\hline Linezolid (36) & $0.00 \%$ & $2.80 \%$ & 1 \\
\hline Colistin (127) & $3.10 \%$ & $3.90 \%$ & 0.11 \\
\hline Vancomycin (65) & $20.00 \%$ & $10.80 \%$ & 1 \\
\hline Type of Infection & $\begin{array}{c}\text { COVID-19 } \\
(n=73)\end{array}$ & $\begin{array}{l}\text { Non-COVID-19 } \\
(n=41)\end{array}$ & $p$ \\
\hline $\mathrm{PN}$ & 48 & 15 & 0.008 \\
\hline BSI & 48 & 21 & 0.19 \\
\hline UTI & 3 & 12 & $<0.001$ \\
\hline Pathogens & $\mathbf{N}=147$ & $N=79$ & \\
\hline Acinetobacter spp. & 67 & 18 & 0.001 \\
\hline Enterococcus spp. & 15 & 13 & 0.21 \\
\hline CoNS & 21 & 6 & 0.2 \\
\hline $\begin{array}{l}\text { Pseudomonas } \\
\text { aeruginosa }\end{array}$ & 12 & 9 & 0.47 \\
\hline Klebsiella spp. & 8 & 10 & 0.07 \\
\hline Proteus mirabilis & 2 & 6 & 0.02 \\
\hline
\end{tabular}

n, number of patients; $\mathrm{N}$, number of isolated pathogens; MET, methicillin; OXA, oxacillin; AMP, ampicillin; AMX, amoxicillin; AMX-CL, amoxicillin-clavulanic acid; PIP-TZ, piperacillin-tazobactam; TMP-SMX, trimethoprimsulfamethoxazole. PN, pneumonia; BSI, bloodstream infection; UTI, urinary tract infection; CoNS, coagulasenegative Staphylococcus; Statistically significant values $(p<0.05)$ in bold.

To determine the appropriate options for empiric and targeted treatment of HAIs, we aggregated overall resistance rates of major antimicrobial groups (penicillins, cephalosporins, 
aminoglycosides, fluoroquinolones, carbapenems, and vancomycin) from this study and our previous study and assessed trends in resistance over four years of follow-up (Figure 1). Absolute numbers of resistance rates can be found in Supplementary Table S1. The aggregation of data shows consistently high resistance rates, reaching $90 \%$ in the last year of follow-up to virtually all antibiotic groups- $99 \%$ for fluoroquinolones, $94 \%$ for carbapenems, $93 \%$ for cephalosporins, and $89 \%$ for penicillins. Vancomycin is the exception, exhibiting much lower resistance rates ( $32 \%$ in the last year). A sharp spike in resistance is seen for carbapenems, rising to from $62 \%$ to $94 \%$ in the last year. Using linear regression and trend analysis (Table 5), we identified that there is a borderline statistically significant positive trend for pathogen resistance to fluoroquinolones $\left(R^{2}=0.904, p=0.05\right)$ and a positive, but not statistically significant trend for carbapenems $\left(R^{2}=0.704, p=0.16\right)$.

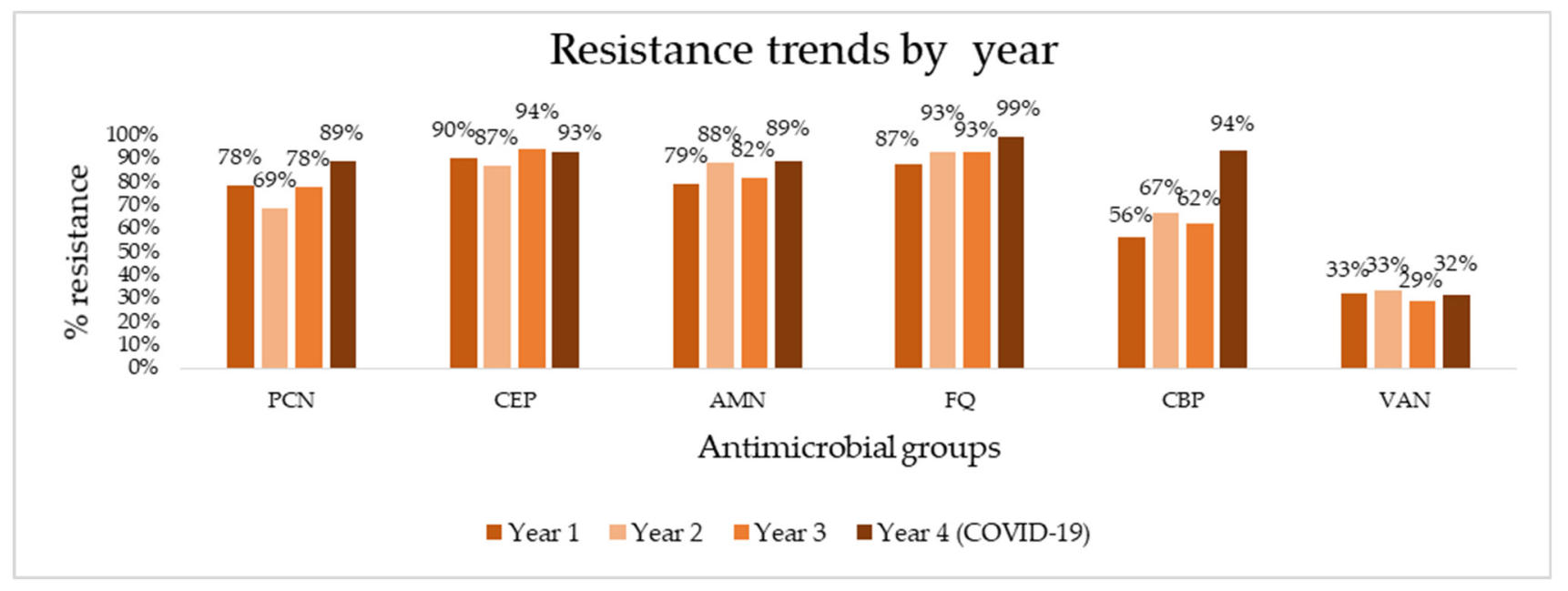

Figure 1. Antimicrobial resistance trends for major antibiotics over four years of surveillance. PCN, penicillins; CEP, cephalosporins; AMN, aminoglycosides; FQ, fluoroquinolones; CBP, carbapenems; VAN, vancomycin.

Table 5. Trend analysis for major antimicrobial groups over four years of follow-up.

\begin{tabular}{cccc}
\hline Isolate & Trend Equation & $\mathbf{R}^{\mathbf{2}}$ & $p$ \\
\hline Penicillins & $\mathrm{y}=4.13 \mathrm{x}+68.10$ & 0.416 & 0.35 \\
Cephalosporins & $\mathrm{y}=1.48 \mathrm{x}+87.18$ & 0.344 & 0.41 \\
Aminoglycosides & $\mathrm{y}=2.15 \mathrm{x}+79.22$ & 0.350 & 0.41 \\
Fluoroquinolones & $\mathrm{y}=3.54 \mathrm{x}+84.14$ & 0.904 & 0.05 \\
Carbapenems & $\mathrm{y}=10.75 \mathrm{x}+42.79$ & 0.700 & 0.16 \\
Vancomycin & $\mathrm{y}=-0.65 \mathrm{x}+33.31$ & 0.223 & 0.53 \\
\hline
\end{tabular}

$\mathrm{R}^{2}$-coefficient of determination.

Trends for overall resistance rates were further investigated by looking at pathogen distribution in the same period (Figure 2) and trend analysis (Table 6). Notable results include a negative, but not statistically significant trend for Klebsella spp. $\left(\mathrm{R}^{2}=0.863\right.$, $p=0.08)$ and positive, but not statistically significant trend for Acinetobacter spp. $\left(\mathrm{R}^{2}=0.721\right.$, $p=0.15)$, which was the most common cause of both PNs and BSIs in our study. 


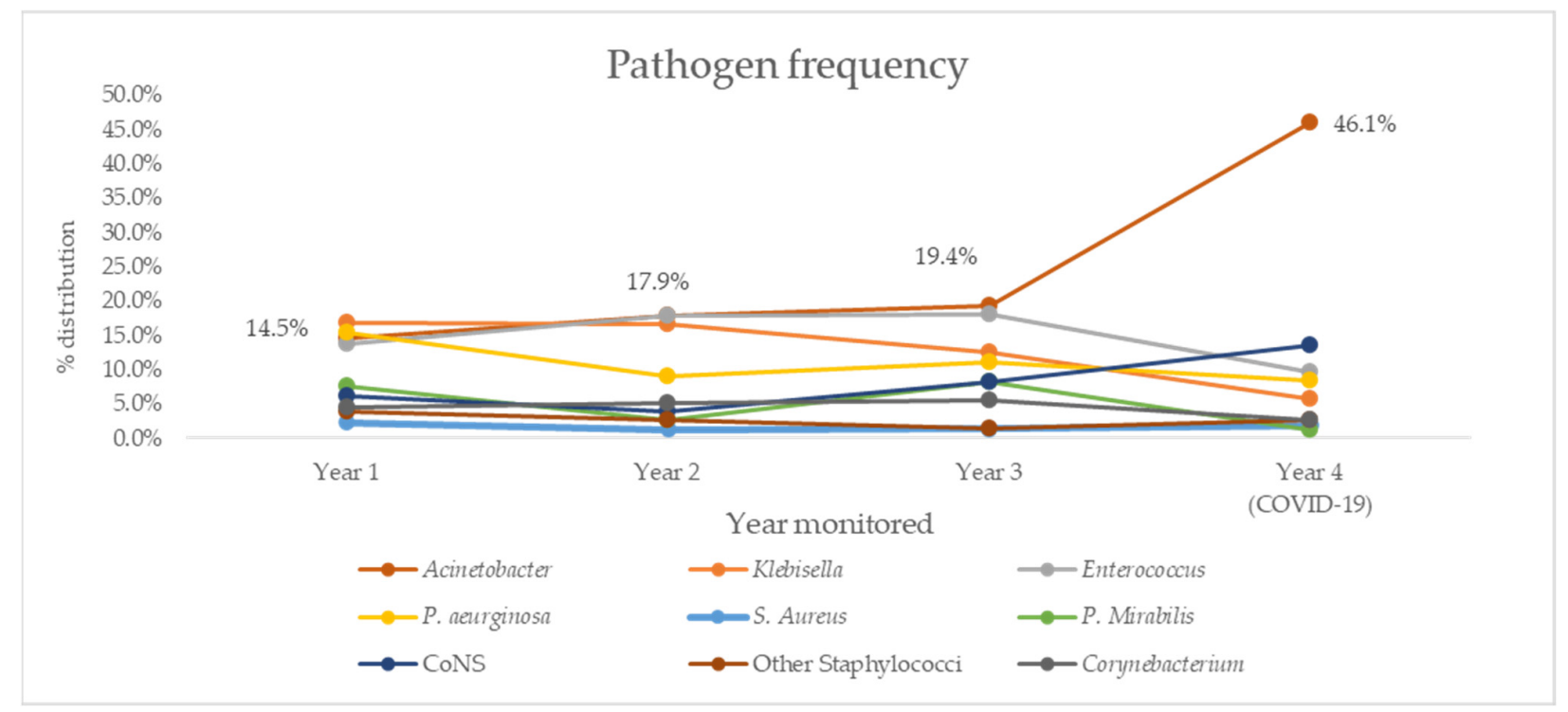

Figure 2. Distribution of most commonly isolated causative agents of HAIs in our ICU over four years of follow-up. CoNS, coagulase-negative Staphylococcus.

Table 6. Trend analysis for most frequently isolated causes of HAI over four years of follow-up.

\begin{tabular}{cccc}
\hline Isolate & Trend Equation & $\mathbf{R}^{\mathbf{2}}$ & $\boldsymbol{p}$ \\
\hline Acinetobacter spp. & $\mathrm{y}=9.63 \mathrm{x}+0.40$ & 0.721 & 0.15 \\
Enterococcus spp. & $\mathrm{y}=-1.18 \mathrm{x}+17.80$ & 0.146 & 0.62 \\
Coagulase-negative Staphylococcus & $\mathrm{y}=2.70 \mathrm{x}+1.20$ & 0.692 & 0.17 \\
Pseudomonas aeruginosa & $\mathrm{y}=-1.86 \mathrm{x}+15.60$ & 0.591 & 0.23 \\
Klebsiella spp. & $\mathrm{y}=-3.72 \mathrm{x}+22.25$ & 0.863 & 0.07 \\
Proteus mirabilis & $\mathrm{y}=-1.32 \mathrm{x}+8.25$ & 0.235 & 0.51 \\
Other Staphylococcal species & $\mathrm{y}=-0.48 \mathrm{x}+3.80$ & 0,400 & 0.37 \\
Staphylococcus aureus & $\mathrm{y}=-0.11 \mathrm{x}+2.00$ & 0.093 & 0.69 \\
Corynebacterium spp. & $\mathrm{y}=-0.55 \mathrm{x}+5.85$ & 0.292 & 0.46 \\
\hline
\end{tabular}

$\mathrm{R}^{2}$-coefficient of determination; statistically significant values $(p<0.05)$ marked in bold.

To understand the drivers of resistance from the perspective of causative agents, a trend analysis for each of the four most frequently isolated pathogens over four years of follow-up (Acinetobacter spp., Klebsiella spp., Enterococcus spp., and Pseudomonas aeruginosa) was conducted (Figure 3). Results show that the resistance profile of Acinetobacter spp. has not significantly changed over time. However, a statistically significant positive trend for resistance to fluoroquinolones $\left(R^{2}=0.980, p=0.01\right)$ and carbapenems $\left(R^{2}=0.963\right.$, $p=0.02)$ is seen for Klebsiella spp., pointing to a change in its resistance profile. Though not statistically significant, a positive trend of resistance to carbapenems $\left(R^{2}=0.845, p=0.08\right)$ is also seen in Enterococcus spp. Absolute numbers of pathogen distribution and resistance rates of individual pathogens can be found in the Supplementary Table S2. 


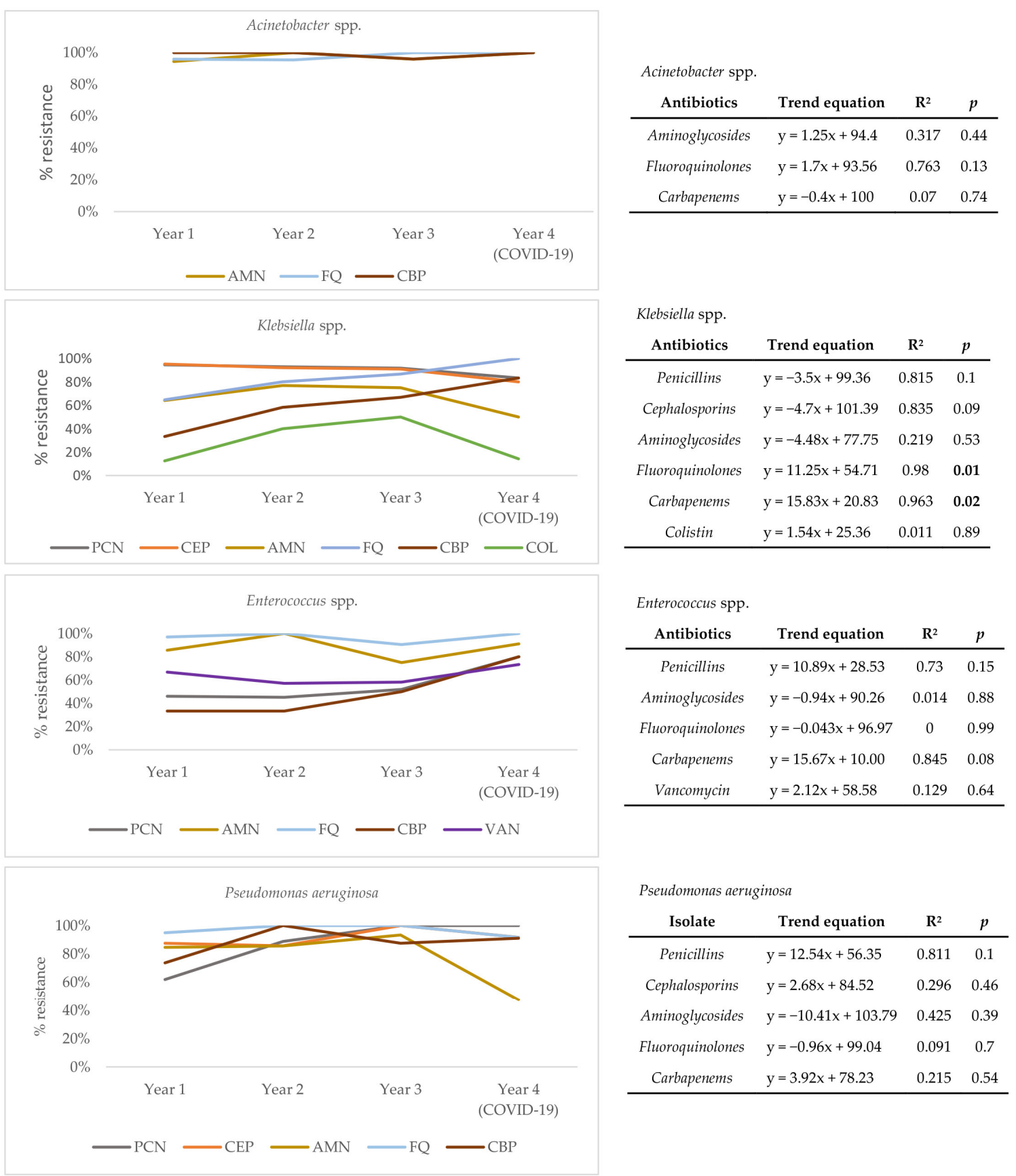

Figure 3. Trends of antimicrobial resistance for Acinetobacter spp., Klebsiella spp., Enterococcus spp., and Pseudomonas aeruginosa isolated over four years of follow-up. AMN, aminoglycosides; FQ, fluoroquinolones; CBP, carbapenems; PCN, penicillins; COL, colistin; VAN, vancomycin; $\mathrm{R}^{2}$ —coefficient of determination; statistically significant values $(p<0.05)$ marked in bold.

The final analysis of our study aggregates AST results over the same four-year period and evaluates which drugs could still be used as empiric treatment for the three most commonly identified HAIs in our ICU-BSIs, PNs, and UTIs (Table 7). 
Table 7. Four-year antimicrobial resistance rates of BSIs, PNs, and UTIs in our ICU.

\begin{tabular}{|c|c|c|c|}
\hline Antibiotics & BSI $(n=158)$ & $\mathrm{PN}(n=123)$ & UTI $(n=108)$ \\
\hline \multicolumn{4}{|l|}{ Penicillins } \\
\hline MET/OXA & $92.9 \%(52 / 56)$ & $100 \%(5 / 5)$ & $\mathrm{N} / \mathrm{A}$ \\
\hline AMP/AMX & $84.8 \%(28 / 33)$ & $87.5 \%(14 / 16)$ & $68.5 \%(37 / 54)$ \\
\hline AMX-CL & $80.0 \%(12 / 15)$ & $80 \%(12 / 15)$ & $59.3 \%(32 / 54)$ \\
\hline PIP-TZ & $77.8 \%(21 / 27)$ & $90.9 \%(30 / 33)$ & $70.5 \%(31 / 44)$ \\
\hline Total & $86.3 \%(113 / 131)$ & $88.4 \%(61 / 69)$ & $66.2 \%(100 / 151)$ \\
\hline \multicolumn{4}{|l|}{ Cephalosporins } \\
\hline Cephalexin & $100 \%(7 / 7)$ & $\mathrm{N} / \mathrm{A}$ & $100 \%(12 / 12)$ \\
\hline Cefotaxime & $100 \%(8 / 8)$ & $\mathrm{N} / \mathrm{A}$ & $100 \%(12 / 12)$ \\
\hline Ceftriaxone & $97.4 \%(38 / 39)$ & $93.9 \%(31 / 33)$ & $88.0 \%(44 / 50)$ \\
\hline Ceftazidime & $94.1 \%(16 / 17)$ & $76.9 \%(10 / 13)$ & $100 \%(16 / 16)$ \\
\hline Total & $97.2 \%(69 / 71)$ & $89.1 \%(41 / 46)$ & $93.3 \%(84 / 90)$ \\
\hline \multicolumn{4}{|l|}{ Aminoglycosides } \\
\hline Gentamicin & $89.9 \%(98 / 109)$ & $93.4 \%(85 / 91)$ & $88.9 \%(64 / 72)$ \\
\hline Amikacin & $74.1 \%(60 / 81)$ & $83.2 \%(79 / 95)$ & $82.1 \%(46 / 56)$ \\
\hline Total & $83.2 \%(158 / 190)$ & $88.2 \%(164 / 186)$ & $85.9 \%(110 / 128)$ \\
\hline \multicolumn{4}{|l|}{ Fluoroquinolones } \\
\hline Ciprofloxacin & $95.0 \%(96 / 101)$ & $96.8 \%(92 / 95)$ & $93.6 \%(73 / 78)$ \\
\hline Levofloxacin & $94.2 \%(98 / 104)$ & $92.2 \%(95 / 103)$ & $86.7 \%(65 / 75)$ \\
\hline Moxifloxacin & $96.4 \%(27 / 28)$ & $\mathrm{N} / \mathrm{A}$ & $\mathrm{N} / \mathrm{A}$ \\
\hline Total & $94.8 \%(221 / 233)$ & $94.4 \%(187 / 198)$ & $90.2 \%(138 / 153)$ \\
\hline \multicolumn{4}{|l|}{ Carbapenems } \\
\hline Imipenem & $83.3 \%(35 / 42)$ & $95.2 \%(60 / 63)$ & $68.8 \%(11 / 16)$ \\
\hline Meropenem & $84.4 \%(38 / 45)$ & $97.2 \%(69 / 71)$ & $90.0 \%(9 / 10)$ \\
\hline Total * & $80.8 \%(97 / 120)$ & $91.3 \%(158 / 173)$ & $53.1 \%(43 / 81)$ \\
\hline \multicolumn{4}{|c|}{ Other Antibiotics } \\
\hline TMP-SMX & $\mathrm{N} / \mathrm{A}$ & $93.8 \%(75 / 80)$ & $87.5 \%(35 / 40)$ \\
\hline Tigecycline & $13.9 \%(5 / 36)$ & $14.3 \%(1 / 7)$ & $27.8 \%(5 / 18)$ \\
\hline Linezolid & $2.6 \%(1 / 39)$ & $\mathrm{N} / \mathrm{A}$ & $0 \%(0 / 21)$ \\
\hline Colistin & $12.9 \%(8 / 62)$ & $0 \%(0 / 98)$ & $12.0 \%(3 / 25)$ \\
\hline Vancomycin & $16.0 \%(12 / 75)$ & $20 \%(1 / 5)$ & $61.1 \%(22 / 36)$ \\
\hline
\end{tabular}

n, number of pathogens isolated; BSI, bloodstream infection; PN, pneumonia; UTI, urinary tract infection; MET, methicillin; OXA, oxacillin; AMP, ampicillin; AMX, amoxicillin; AMX-CL, amoxicillin-clavulanic acid; PIP-TAZ, piperacillin-tazobactam; TMP-SMX, trimethoprim-sulfamethoxazole. N/A, no results available; * In years 1 and 2 of follow-up (during our previous study), carbapenem resistance was noted as resistance to either imipenem or meropenem.

For causative agents of BSIs we see significant resistance rates to all major antimicrobial groups-97.2\% for cephalosporins, $94.8 \%$ for fluoroquinolones, $86.3 \%$ for penicillins, and $80.8 \%$ for carbapenems. Resistance to vancomycin $(16.0 \%)$, tigecycline $(13.9 \%)$, colistin $(12.9 \%)$, and linezolid $(2.6 \%)$ remains low. Similar results are seen in PNs, where only tigecycline $(14.3 \%)$ and colistin ( $0 \%)$ exhibit low resistance rates. When it comes to UTIs, very high resistance rates are present for cephalosporins (93.3\%), fluoroquinolones $(90.2 \%)$, TMP-SMX ( $87.5 \%)$ and aminoglycosides (85.9\%). Somewhat lower, but still high resistance rates are present for penicillins (66.2\%), vancomycin (61.1\%) and carbapenems $(53.1 \%)$, with only colistin $(12.0 \%)$ and linezolid $(0 \%)$ exhibiting low resistance rates to pathogens responsible for this type of infection.

\section{Discussion}

Our study describes the profile of HAIs in our ICU over a two-year period and their change in profile during the COVID-19 pandemic. The resistance rates of HAIs to the majority of antibiotics that are currently approved for empiric, but also targeted therapy in our country are extremely high. Compared to all EU/EEA countries and international reports, our findings show much higher resistance rates, with only Romania and Greece reporting somewhat comparable results for certain antimicrobial groups $[1,21]$. Furthermore, our results are consistent with the Central Asian and European Surveillance 
of Antimicrobial Resistance (CAESAR) reports from our country, where resistance to pathogens such as A. baumannii exceeds $90 \%$ for all tested antibiotics [22]. The only drugs that exhibited fairly low overall resistance rates were linezolid and colistin. Linezolid resistance across Europe and worldwide remains low [23,24], but colistin-resistant HAIs in ICUs are becoming a concern $[25,26]$. Colistin plays a crucial role in treatment of MDR infections, and efforts toward determining colistin resistance on a larger scale are ongoing [27]. Studies in our country have indeed identified emerging colistin resistance with similar results [28].

The problem of such high AMR in Serbia stems, at least in part, from poor overall antimicrobial stewardship. Prescribing rates have significantly grown over the past decade are much higher than the European average [29]. Furthermore, the excessive and irrational use of antibiotics occurs through self-prescribing practices that are still possible in our country, but also poor adherence to national guidelines for rational antimicrobial use [30,31]. This is unfortunate, as studies from Serbian hospitals have shown that resistance rates can decline through adequate surveillance and changes in antibiotic prescribing [32]. Education plays a significant role as well, with recent studies showing a limited understanding regarding proper use of antibiotics in Serbian general population. [33] Our findings, although dealing with HAIs rather than community-acquired infections, reiterate the critical role of local surveillance in determining optimal therapeutic strategies $[1,16]$.

When it comes to COVID-19 and its impact on HAIs in our study, we see a significant shift in the type of infection, causative agents, and resistance profiles. Though not unexpected, the rise of PNs, many of which caused by CRA, brings a new challenge when it comes to HAI management. Increased rates of HAIs in ICUs that treat COVID-19 patients are being reported in various countries and support our findings [4,34], likely as a result of the inability to fully comply with the standard practices of infection control during this unprecedented time $[12,35,36]$. Another risk for promoting resistance in patients hospitalized for COVID-19 is the use of immunosuppressive therapy, though studies are showing conflicting results regarding its contribution to resistance [37,38]. Serbia's national guideline for COVID-19 treatment (provided in Supplementary Table S3) emphasizes the absolute avoidance of antibiotic use precisely because of the risk of rising AMR. Moreover, in-hospital use of antibiotics has known to be a driver of resistance in a time-dependent manner [39], pointing to a need for rational use of antimicrobials across all levels of care.

The trend analysis of antimicrobial resistance shows that the increased presence of Acinetobacter spp. (with stable resistance to fluoroquinolones and carbapenems over the years), coupled with the statistically significant positive trend of Klebsiella spp. resistance to the two antibiotic groups, could be responsible for the current situation in our ICU. Carbapenem-resistant Klebsiella infections in COVID-19 patients treated in ICUs have indeed been documented $[13,14]$. Knowing the mechanism by which resistance developed could be crucial in determining optimal infection control practices and new therapeutic options as the pandemic continues. The acquisition of resistance is known to be an important component of overall antimicrobial stewardship for HAIs in ICUs [40-42]. Coupled with investigating this, infection control efforts aimed at Acinetobacter spp. and Enterobacteriaceae should be rigorously implemented to help reduce their occurrence in our ICU [43,44].

This brings us to the final topic of our study-choice of empiric therapy. In the case of BSIs, we see that currently used penicillins, cephalosporins, aminoglycosides, fluoroquinolones, and carbapenems are not fit for use as empiric, or even targeted therapy. Vancomycin is still a viable antibiotic for empiric treatment of BSIs according to our results, but is at risk of reaching higher rates of resistance already appearing in other countries $[45,46]$.

For PNs, virtually all drugs available in our country, also listed in major international guidelines, exhibited very high resistance rates, thus limiting their use as empiric therapy $[47,48]$. Colistin and tigecycline remain the only antibiotics in our setting, though their use in such capacity is not substantiated by high-quality evidence [48-50]. In fact, 
tigecycline is not recommended if Acinetobacter spp. are causative agents of PN, which was predominantly the case in our study $[48,51]$.

When it comes to UTIs, we see a similar situation in that high resistance rates are seen for most tested antibiotics. Because most UTIs in our ICU are CAUTIs, the use of amoxicillin, aminoglycosides, third-generation cephalosporins, and ciprofloxacin as empiric therapy, all of them recommended in European guidelines, is not viable [52]. In addition, resistance rates of $61.1 \%$ for vancomycin makes a difficult case for its use as empiric therapy. Unless urosepsis is suspected, deferring therapy until AST reveals good candidates for targeted treatment may be a wiser approach [53], as Linezolid and tigecycline seem to be only viable options for empiric CAUTI treatment in our setting.

Decreasing the time from obtaining samples for analysis to getting results could help in facilitating earlier initiation of treatment for HAIs in general. The development of "rapid antimicrobial susceptibility testing" (RAST) provides AST results within hours [54], but a number of other methods are being developed and used with equal reduction in time to results $[55,56]$. Such practices must become the gold standard in our laboratories, as earlier initiation of effective therapy significantly improves patient outcomes [57].

The need for new drugs, especially as the COVID-19 pandemic continues, is perhaps the most important step our country needs to take in order to successful manage HAIs, both for COVID-19 patients and across other ICUs. In recent years, several drugs have been approved for treatment of MDR pathogens and different types of HAIs in the European Union (EU) and the United States (US) [58-60], both as standalone drugs and combination therapies, whereas a number of drugs are being investigated through clinical trials [61,62]. Aztreonam, considered an "old" drug, has also shown to be a useful agent in treating MDR infections as an adjunct to some of the recently approved antibiotics [63,64]. With our findings, the case has been made for urgent approval of new drugs for HAI treatment in Serbia.

There are several limitations of our study that need to be pointed out, starting with those related to the retrospective study design. First, we were limited in our capacity to look at the relationship between the choice of empiric therapy, its potential change to targeted therapy and the overall effects of HAIs on patient outcomes. Second, it also limited our ability to look at the interaction between antimicrobial use that extends beyond window of $48 \mathrm{~h}$ before and after admission, given the established relationship of prolonged antimicrobial use and development of resistance [65]. And third, the extent to which immunosuppressive drugs (such as corticosteroids and/or tocilizumab) used in COVID-19 treatment played a role in the development of AMR [12].

Additionally, our results are from only one type of ICU, that of treating exclusively infectious diseases and currently dealing with COVID-19 patients. By including other types of ICUs such as surgical, cardiovascular, and pediatric/neonatal, thereby increasing the sample size as well, would help understand the potential differences in pathogen profiles and resistance rates. These findings could improve national recommendations for empiric therapy and put a stronger emphasis on both new drug approval and better diagnostics.

Finally, the inconsistencies in AST seen above are a consequence of implementing the European Committee on Antimicrobial susceptibility testing (EUCAST) recommendations that vary between pathogens [54], and in some instances, our inability to adhere to the recommendations to their full extent. As a result, we were not able to establish rates of extensive-drug resistant and pan-drug resistant (XDR/PDR) pathogens in our ICU [66]. To perform such classification, comprehensive panels of testing are required, including drugs that are not currently available for use in our country.

\section{Materials and Methods}

\subsection{Study Design}

This two-year retrospective study included all patients that were admitted and discharged between April 2019 and April 2021 from the 16-bed adult ICU of the 150-bed Teaching Hospital for Infectious and Tropical Diseases, University Clinical Center of Serbia. 
Since the start of the COVID-19 pandemic, which coincided with the beginning of the second year of follow-up in our study, the ICU of our hospital has been tasked with primarily caring for severe COVID-19 patients requiring intensive care. During the two-year period, health care records from a total of 673 patients over 18 years old were evaluated (as our hospital treats only adult patients). Criteria for exclusion were a length of stay $<48 \mathrm{~h}$ $(n=58)$ and incomplete patient record data $(n=4)$. Patients in whom a diagnosis of HAI as a result of stay in our ICU was not made $(n=497)$ were excluded from the final analysis.

Patients in whom one or more distinct HAI episodes were diagnosed and for which AST results were available were included in the study. Comparisons between causative agents of HAIs and their resistance rates were made in COVID-19 patients, who comprised the majority of patients during the second year of our study (1 April 2020-31 March 2021), and patients without a COVID-19 diagnosis, the majority being admitted during the prepandemic year (1 April 2019-31 March 2020). The obtained results from this study were then aggregated with data from our previous study to derive four-year trends of resistance across different antimicrobial groups and overall resistance of pathogens responsible for causing the most frequently identified HAIs-BSIs, PNs, and UTIs. In addition, pathogen frequencies and trends of antimicrobial resistance for four of the most frequently isolated pathogens over the same period (Acinetobacter spp., Klebsiella spp., Enterococcus spp., and Pseudomonas aeruginosa) to major antibiotic groups were investigated.

\subsection{Definitions and Data Collection}

Each episode of ICU-acquired HAI was defined and categorized using the European Center for Disease Control (eCDC) criteria, occurring $\geq 48$ hours after admission, with onset from day 3 onwards and day 1 being the date of admission [67]. These criteria allowed us to exclude patients in whom HAIs developed before admission to our ICU, such as cases in which HAIs developed in facilities where they were previously hospitalized. As a result, HAI from our ICU types included bloodstream infections (BSI), pneumonia $(\mathrm{PN})$, urinary tract infections (UTI), central nervous system infection (CNS), eye, ear, nose or mouth infection (EENT), skin and soft tissue infections (SST), and reproductive tract infections (REPR) [68]. Assessment of multidrug resistant (MDR) pathogens was conducted using standardized susceptibility criteria-resistance to at least one antibiotic from at least three groups of antimicrobial drugs [66]. Both AST and pathogen identification at our hospital is conducted using Vitek $2{ }^{\circledR}$ bioMerieux, guided by the EUCAST breakpoints and recommendations, with intermediately resistant results being classified as resistant [69]. The antibiotic groups that have been tested included: penicillins (methicillin-oxacillin, MET-OXA; ampicillin/amoxicillin, AMP/AMX; amoxicillin-clavulanic acid, AMX-CL; piperacillin-tazobactam, PIP-TZ), cephalosporins (cephalexin, cefotaxime, ceftriaxone, ceftazidime), aminoglycosides (gentamicin, amikacin), fluoroquinolones (ciprofloxacin, levofloxacin, moxifloxacin), carbapenems (imipenem, meropenem, ertapenem), glycopeptides (vancomycin, teicoplanin), trimethoprim-sulfamethoxazole (TMP-SMX), linezolid, tigecycline, and colistin.

Data collected from patient records included basic demographic and clinical characteristics (age, biological sex, date of admission and discharge to determine LOS, type of admission, primary diagnosis, comorbidities, antimicrobial use $48 \mathrm{~h}$ prior to and after admission). Additionally, dates of invasive device placement and removal, including urinary catheters, central venous catheters, respiratory tubes, and mechanical ventilation was collected to determine if HAIs were device-associated, in line with eCDC criteria [67]. Dates of HAI sampling and source of acquisition were collected, together with AST results.

\subsection{Data Analysis}

The Statistical Package for Social Sciences (SPSS) software version 23 (IBM Corp. Released 2015. IBM SPSS Statistics for Windows, Version 23.0. Armonk, NY, USA: IBM Corp.) was used for analysis of patient data. Mean and standard deviation were used to describe variables that exhibited normal distribution, whereas median and interquartile 
range (IQR) were used to describe variables that did not exhibit normal distribution. Numbers and percentages were used to describe the distribution of pathogens responsible for HAIs, as well as antimicrobial resistance rates, both overall and stratified across most common HAI types.

Chi-square test was used to determine the association between a COVID-19 diagnosis and the following variables: resistance rates to individual antibiotics, infection types (PN, BSI, UTI), and individual pathogens (Acinetobacter spp., Klebsiella spp., coagulase-negative Staphylococcus, Pseudomonas aeruginosa, Enterococcus spp., Proteus mirabilis). Using linear regression, we investigated trends of antimicrobial resistance rates and pathogen distribution across four years of follow-up. For antimicrobial resistance rates, trend analysis was firstly conducted by combining all pathogens responsible for HAIs across six antimicrobial groups (penicillins, cephalosporins, aminoglycosides, fluoroquinolones, carbapenems, and vancomycin). This was followed by a separate analysis for the most frequently isolated agents over four years of follow-up (Acinetobacter spp., Klebsiella spp., Enterococcus spp., and Pseudomonas aeruginosa) for applicable antimicrobial groups. For all statistical tests used in the study, $p$ values $<0.05$ were considered statistically significant.

All data that were included in the analysis were previously anonymized. The manuscript was prepared in accordance with the STROBE statement, attached in Supplementary Table S4.

\section{Conclusions}

As a result of managing COVID-19 patients, our study showed a significant shift in the landscape of HAIs in our ICU compared to previous years. Acinetobacter spp. and Klebsiella spp. are pathogens that are driving resistance to carbapenems and fluoroquinolones, leaving limited options for empiric and targeted therapy. Immediate approval of new drugs for treatment of hospital-acquired BSIs, PNs, and UTIs is needed. Implementation of faster microbiological diagnostics is necessary to ensure early initiation of optimal treatment for every patient. Surveillance needs to be continued and expanded both in terms of antibiotics subjected to testing and other ICUs to revise local treatment guidelines as the pandemic continues.

Supplementary Materials: The following are available online at https:/ /www.mdpi.com/article/10 .3390/antibiotics10101146/s1, Table S1: Resistance rates of each antibiotic included in trend analysis over a four-year period; Table S2: Absolute numbers of pathogens distribution and resistance rates of individual pathogens; Table S3: Serbian National COVID-19 Treatment Guidelines; Table S4: STROBE Checklist for Cohort studies.

Author Contributions: Conceptualization, A.D. and G.S.; methodology, A.D., B.M. and A.C.; formal analysis, A.V. and A.C.; data curation, A.V., K.C., T.C.; writing—original draft preparation, A.D. and G.S.; writing-review and editing, A.D., B.M., A.V., T.C., K.C. and A.C.; visualization, A.D. and A.C.; supervision, G.S.; project administration, A.D.; funding acquisition A.D. All authors have read and agreed to the published version of the manuscript.

Funding: This research has received no external funding.

Institutional Review Board Statement: The study was conducted according to the guidelines of the Declaration of Helsinki, and approved by the Ethics Committee of the University Clinical Center of Serbia (Decision No. 687/I, titled "Investigation of Hospital-Acquired Infections in Intensive Care Units", approved 6 October 2020).

Informed Consent Statement: Not applicable.

Data Availability Statement: The majority of the data supporting the results of this study are located in the Supplementary Materials of this manuscript. Any additional information can be available on request to the corresponding author.

Acknowledgments: We thank the entire administrative and hospital staff at the Teaching Hospital for Infectious and Tropical Diseases, University Clinical Center of Serbia, for their bravery and selflessness during the COVID-19 pandemic. This study would not be possible without their efforts.

Conflicts of Interest: The authors declare no conflict of interest. 


\section{References}

1. Suetens, C.; Latour, K.; Kärki, T.; Ricchizzi, E.; Kinross, P.; Moro, M.L.; Jans, B.; Hopkins, S.; Hansen, S.; Lyytikäinen, O.; et al. Prevalence of healthcare-associated infections, estimated incidence and composite antimicrobial resistance index in acute care hospitals and long-term care facilities: Results from two european point prevalence surveys, 2016 to 2017. Eurosurveillance 2018, 23, 1-17. [CrossRef]

2. Cassini, A.; Högberg, L.D.; Plachouras, D.; Quattrocchi, A.; Hoxha, A.; Simonsen, G.S.; Colomb-Cotinat, M.; Kretzschmar M.E.; Devleesschauwer, B.; Cecchini, M.; et al. Attributable deaths and disability-adjusted life-years caused by infections with antibiotic-resistant bacteria in the EU and the European Economic Area in 2015: A population-level modelling analysis. Lancet Infect. Dis. 2019, 19, 56-66. [CrossRef]

3. Kärki, T.; Plachouras, D.; Cassini, A.; Suetens, C. Burden of healthcare-associated infections in European acute care hospitals. Wien. Med. Wochenschr. 2019, 169, 3-5. [CrossRef]

4. Grasselli, G.; Scaravilli, V.; Mangioni, D.; Scudeller, L.; Alagna, L.; Bartoletti, M.; Bellani, G.; Biagioni, E.; Bonfanti, P.; Bottino, N.; et al. Hospital-Acquired Infections in Critically Ill Patients With COVID-19. Chest 2021, 160, 454-465. [CrossRef]

5. Bardi, T.; Pintado, V.; Gomez-Rojo, M.; Escudero-Sanchez, R.; Azzam Lopez, A.; Diez-Remesal, Y.; Martinez Castro, N.; RuizGarbajosa, P.; Pestaña, D. Nosocomial infections associated to COVID-19 in the intensive care unit: Clinical characteristics and outcome. Eur. J. Clin. Microbiol. Infect. Dis. 2021, 40, 495-502. [CrossRef]

6. Smith, L.; Karaba, S.M.; Amoah, J.; Jones, G.; Avery, R.K.; Dzintars, K.; Helsel, T.; Cosgrove, S.E.; Fabre, V. Hospital-acquired infections among adult patients admitted for coronavirus disease 2019 (COVID-19). Infect. Control Hosp. Epidemiol. 2021, 1-4. [CrossRef]

7. Schreiber, P.W.; Sax, H.; Wolfensberger, A.; Clack, L.; Kuster, S.P. The preventable proportion of healthcare-associated infections 2005-2016: Systematic review and meta-analysis. Infect. Control Hosp. Epidemiol. 2018, 39, 1277-1295. [CrossRef] [PubMed]

8. Saini, V.; Jain, C.; Singh, N.P.; Alsulimani, A.; Gupta, C.; Dar, S.A.; Haque, S.; Das, S. Paradigm Shift in Antimicrobial Resistance Pattern of Bacterial Isolates during the COVID-19 Pandemic. Antibiotics 2021, 10, 954. [CrossRef]

9. Rawson, T.M.; Moore, L.S.P.; Castro-Sanchez, E.; Charani, E.; Davies, F.; Satta, G.; Ellington, M.J.; Holmes, A.H. COVID-19 and the potential long-term impact on antimicrobial resistance. J. Antimicrob. Chemother. 2020, 75, 1681-1684. [CrossRef] [PubMed]

10. Bonomo, R.A.; Burd, E.M.; Conly, J.; Limbago, B.M.; Poirel, L.; Segre, J.A.; Westblade, L.F. Carbapenemase-Producing Organisms: A Global Scourge. Clin. Infect. Dis. 2018, 66, 1290-1297. [CrossRef] [PubMed]

11. Gottesman, T.; Fedorowsky, R.; Yerushalmi, R.; Lellouche, J.; Nutman, A. An outbreak of carbapenem-resistant Acinetobacter baumannii in a COVID-19 dedicated hospital. Infect. Prev. Pract. 2021, 3, 100113. [CrossRef] [PubMed]

12. Russo, A.; Gavaruzzi, F.; Ceccarelli, G.; Borrazzo, C.; Oliva, A.; Alessandri, F.; Magnanimi, E.; Pugliese, F.; Venditti, M. Multidrugresistant Acinetobacter baumannii infections in COVID-19 patients hospitalized in intensive care unit. Infection 2021, 1-10. [CrossRef]

13. Dumitru, I.M.; Dumitrascu, M.; Vlad, N.D.; Cernat, R.C.; Ilie-Serban, C.; Hangan, A.; Slujitoru, R.E.; Gherghina, A.; Mitroi-Maxim, C.; Curtali, L.; et al. Carbapenem-Resistant Klebsiella pneumoniae Associated with COVID-19. Antibiotics 2021, 10, 561. [CrossRef]

14. Gomez-Simmonds, A.; Annavajhala, M.K.; McConville, T.H.; Dietz, D.E.; Shoucri, S.M.; Laracy, J.C.; Rozenberg, F.D.; Nelson, B.; Greendyke, W.G.; Furuya, E.Y.; et al. Carbapenemase-producing Enterobacterales causing secondary infections during the COVID-19 crisis at a New York City hospital. J. Antimicrob. Chemother. 2021, 76, 380-384. [CrossRef]

15. Campion, M.; Scully, G. Antibiotic Use in the Intensive Care Unit: Optimization and De-Escalation. J. Intensive Care Med. 2018, 33, 647-655. [CrossRef]

16. Tacconelli, E.; Sifakis, F.; Harbarth, S.; Schrijver, R.; van Mourik, M.; Voss, A.; Sharland, M.; Rajendran, N.B.; Rodríguez-Baño, J. Surveillance for control of antimicrobial resistance. Lancet Infect. Dis. 2018, 18, e99-e106. [CrossRef]

17. Šuljagić, V.; Bajčetić, M.; Mioljević, V.; Dragovac, G.; Mijović, B.; Janićijević, I.; Đorđević, Z.; Krtinić, G.; Rakić, V.; Ćirković, I.; et al. A nationwide assessment of the burden of healthcare-associated infections and antimicrobial use among surgical patients: Results from Serbian point prevalence survey, 2017. Antimicrob. Resist. Infect. Control 2021, 10, 47. [CrossRef]

18. Djuric, O.; Markovic-Denic, L.; Jovanovic, B.; Jovanovic, S.; Marusic, V.; Bumbasirevic, V. Bacterial bloodstream infections in level-I trauma intensive care unit in Serbia: Incidence, causative agents and outcomes. J. Infect. Dev. Ctries. 2018, 12, $1079-1087$. [CrossRef]

19. Djordjevic, Z.M.; Folic, M.M.; Jankovic, S.M. Distribution and antibiotic susceptibility of pathogens isolated from adults with hospital-acquired and ventilator-associated pneumonia in intensive care unit. J. Infect. Public Health 2017, 10, 740-744. [CrossRef] [PubMed]

20. Despotovic, A.; Milosevic, B.; Milosevic, I.; Mitrovic, N.; Cirkovic, A.; Jovanovic, S.; Stevanovic, G. Hospital-acquired infections in the adult intensive care unit-Epidemiology, antimicrobial resistance patterns, and risk factors for acquisition and mortality. Am. J. Infect. Control 2020, 48, 1211-1215. [CrossRef] [PubMed]

21. Rosenthal, V.D.; Duszynska, W.; Ider, B.-E.; Gurskis, V.; Al-Ruzzieh, M.A.; Myatra, S.N.; Gupta, D.; Belkebir, S.; Upadhyay, N.; Zand, F.; et al. International Nosocomial Infection Control Consortium (INICC) report, data summary of 45 countries for 2013-2018, Adult and Pediatric Units, Device-associated Module. Am. J. Infect. Control 2021, in press. [CrossRef]

22. World Health Organization. Central Asian and European Surveillance of Antimicrobial Resistance, Annual Report 2020; World Health Organization: Geneva, Switzerland, 2020. 
23. Markwart, R.; Willrich, N.; Eckmanns, T.; Werner, G.; Ayobami, O. Low Proportion of Linezolid and Daptomycin Resistance Among Bloodborne Vancomycin-Resistant Enterococcus faecium and Methicillin-Resistant Staphylococcus aureus Infections in Europe. Front. Microbiol. 2021, 12, 664199. [CrossRef]

24. Maarouf, L.; Omar, H.; El-Nakeeb, M.; Abouelfetouh, A. Prevalence and mechanisms of linezolid resistance among staphylococcal clinical isolates from Egypt. Eur. J. Clin. Microbiol. Infect. Dis. 2021, 40, 815-823. [CrossRef]

25. El-Mokhtar, M.A.; Daef, E.; Mohamed Hussein, A.A.R.; Hashem, M.K.; Hassan, H.M. Emergence of Nosocomial Pneumonia Caused by Colistin-Resistant Escherichia coli in Patients Admitted to Chest Intensive Care Unit. Antibiotics 2021, $10,226$. [CrossRef] [PubMed]

26. Papathanakos, G.; Andrianopoulos, I.; Papathanasiou, A.; Priavali, E.; Koulenti, D.; Koulouras, V. Colistin-Resistant Acinetobacter Baumannii Bacteremia: A Serious Threat for Critically Ill Patients. Microorganisms 2020, 8, 287. [CrossRef]

27. European Centre for Disease Prevention and Control. ECDC Study Protocol for Genomic-Based Surveillance of Carbapenem-Resistant and/or Colistin-Resistant Enterobacteriaceae at the EU Level. Version 2.0; ECDC: Stockholm, Sweden, 2018.

28. Popović, R.; Tomić, Z.; Tomas, A.; Anđelić, N.; Vicković, S.; Jovanović, G.; Bukumirić, D.; Horvat, O.; Sabo, A. Five-year surveillance and correlation of antibiotic consumption and resistance of Gram-negative bacteria at an intensive care unit in Serbia. J. Chemother. 2020, 32, 294-303. [CrossRef] [PubMed]

29. Tomas, A.; Pavlović, N.; Stilinović, N.; Horvat, O.; Paut-Kusturica, M.; Dugandžija, T.; Tomić, Z.; Sabo, A. Increase and Change in the Pattern of Antibiotic Use in Serbia (2010-2019). Antibiotics 2021, 10, 397. [CrossRef] [PubMed]

30. Horvat, O.; Mijatović, V.; Milijasević, B.; Tomas, A.; Kusturica, M.P.; Tomić, Z.; Sabo, A. Are There Striking Differences in Outpatient Use of Antibiotics Between South Backa District, Serbia, and Some Scandinavian Countries? Front. Public Health 2018, 6, 91. [CrossRef]

31. Radna Grupa za Izradu Nacionalnog Vodica Dobre Klinicke Prakse Ministarstva Zdravlja Republike Srbije. Nacionalni Vodic Dobre Klinicke Prakse. Racionalna Upotreba Antibiotika; Ministarstvo Zdravlja Republike Srbije: Belgrade, Serbia, 2018.

32. Djordjevic, Z.M.; Folic, M.M.; Jankovic, S.M. Correlation between cefepime utilisation and Pseudomonas aeruginosa resistance rates to $\beta$-lactams and carbapenems in patients with healthcare-associated infections. J. Glob. Antimicrob. Resist. 2018, $13,60-64$. [CrossRef]

33. Horvat, O.J.; Tomas, A.D.; Paut Kusturica, M.M.; Savkov, A.V.; Bukumirić, D.U.; Tomić, Z.S.; Sabo, A.J. Is the level of knowledge a predictor of rational antibiotic use in Serbia? PLoS ONE 2017, 12, e0180799. [CrossRef]

34. Llitjos, J.-F.; Bredin, S.; Lascarrou, J.-B.; Soumagne, T.; Cojocaru, M.; Leclerc, M.; Lepetit, A.; Gouhier, A.; Charpentier, J.; Piton, G.; et al. Increased susceptibility to intensive care unit-acquired pneumonia in severe COVID-19 patients: A multicentre retrospective cohort study. Ann. Intensive Care 2021, 11, 20. [CrossRef] [PubMed]

35. McGovern, P.C.; Wible, M.; El-Tahtawy, A.; Biswas, P.; Meyer, R.D. All-cause mortality imbalance in the tigecycline phase 3 and 4 clinical trials. Int. J. Antimicrob. Agents 2013, 41, 463-467. [CrossRef]

36. Pascale, R.; Bussini, L.; Gaibani, P.; Bovo, F.; Fornaro, G.; Lombardo, D.; Ambretti, S.; Pensalfine, G.; Appolloni, L.; Bartoletti, M.; et al. Carbapenem-resistant bacteria in an intensive care unit during the coronavirus disease 2019 (COVID-19) pandemic: A multicenter before-and-after cross-sectional study. Infect. Control Hosp. Epidemiol. 2021, 1-6. [CrossRef] [PubMed]

37. Abelenda-Alonso, G.; Rombauts, A.; Gudiol, C.; Oriol, I.; Simonetti, A.; Coloma, A.; Rodríguez-Molinero, A.; Izquierdo, E.; Díaz-Brito, V.; Sanmartí, M.; et al. Immunomodulatory therapy, risk factors and outcomes of hospital-acquired bloodstream infection in patients with severe COVID-19 pneumonia: A Spanish case-control matched multicentre study (BACTCOVID). Clin. Microbiol. Infect. 2021, in press. [CrossRef]

38. Khatri, A.; Malhotra, P.; Izard, S.; Kim, A.; Oppenheim, M.; Gautam-Goyal, P.; Chen, T.; Doan, T.; Berlinrut, I.; Niknam, N.; et al. Hospital-Acquired Bloodstream Infections in Patients Hospitalized with Severe Acute Respiratory Syndrome Coronavirus 2 Infection (Coronavirus Disease 2019): Association with Immunosuppressive Therapies. Open Forum Infect. Dis. 2021, 8, ofab339. [CrossRef]

39. Kousovista, R.; Athanasiou, C.; Liaskonis, K.; Ivopoulou, O.; Ismailos, G.; Karalis, V. Correlation between Acinetobacter baumannii Resistance and Hospital Use of Meropenem, Cefepime, and Ciprofloxacin: Time Series Analysis and Dynamic Regression Models. Pathogens 2021, 10, 480. [CrossRef]

40. Galani, I.; Karaiskos, I.; Giamarellou, H. Multidrug-resistant Klebsiella pneumoniae: Mechanisms of resistance including updated data for novel $\beta$-lactam- $\beta$-lactamase inhibitor combinations. Expert Rev. Anti-Infect. Ther. 2021, 1-12. [CrossRef] [PubMed]

41. Nguyen, M.; Joshi, S.G. Carbapenem resistance in Acinetobacter baumannii, and their importance in hospital-acquired infections: A scientific review. J. Appl. Microbiol. 2021. [CrossRef]

42. Doi, Y. Treatment Options for Carbapenem-resistant Gram-negative Bacterial Infections. Clin. Infect. Dis. 2019, 69, S565-S575. [CrossRef] [PubMed]

43. World Health Organization. Guidelines for the Prevention and Control of Carbapenem-Resistant Enterobacteriaceae, Acinetobacter baumannii and Pseudomonas aeruginosa in Health Care Facilities; WHO: Geneva, Switzerland, 2017.

44. Weinberg, S.E.; Villedieu, A.; Bagdasarian, N.; Karah, N.; Teare, L.; Elamin, W.F. Control and management of multidrug resistant Acinetobacter baumannii: A review of the evidence and proposal of novel approaches. Infect. Prev. Pract. 2020, 2, 100077. [CrossRef] 
45. Remschmidt, C.; Schröder, C.; Behnke, M.; Gastmeier, P.; Geffers, C.; Kramer, T.S. Continuous increase of vancomycin resistance in enterococci causing nosocomial infections in Germany - 10 years of surveillance. Antimicrob. Resist. Infect. Control 2018, 7, 54. [CrossRef]

46. Wu, Q.; Sabokroo, N.; Wang, Y.; Hashemian, M.; Karamollahi, S.; Kouhsari, E. Systematic review and meta-analysis of the epidemiology of vancomycin-resistance Staphylococcus aureus isolates. Antimicrob. Resist. Infect. Control 2021, 10, 101. [CrossRef]

47. Torres, A.; Niederman, M.S.; Chastre, J.; Ewig, S.; Fernandez-Vandellos, P.; Hanberger, H.; Kollef, M.; Li Bassi, G.; Luna, C.M.; Martin-Loeches, I.; et al. Summary of the international clinical guidelines for the management of hospital-acquired and ventilator-acquired pneumonia. ERJ Open Res. 2018, 4, 28-2018. [CrossRef]

48. Kalil, A.C.; Metersky, M.L.; Klompas, M.; Muscedere, J.; Sweeney, D.A.; Palmer, L.B.; Napolitano, L.M.; O’Grady, N.P.; Bartlett, J.G.; Carratalà, J.; et al. Management of Adults with Hospital-acquired and Ventilator-associated Pneumonia: 2016 Clinical Practice Guidelines by the Infectious Diseases Society of America and the American Thoracic Society. Clin. Infect. Dis. 2016, 63, e61-e111. [CrossRef] [PubMed]

49. Cisneros, J.M.; Rosso-Fernández, C.M.; Roca-Oporto, C.; De Pascale, G.; Jiménez-Jorge, S.; Fernández-Hinojosa, E.; Matthaiou, D.K.; Ramírez, P.; Díaz-Miguel, R.O.; Estella, A.; et al. Colistin versus meropenem in the empirical treatment of ventilatorassociated pneumonia (Magic Bullet study): An investigator-driven, open-label, randomized, noninferiority controlled trial. Crit. Care 2019, 23, 383. [CrossRef] [PubMed]

50. Florescu, D.F.; Qiu, F.; McCartan, M.A.; Mindru, C.; Fey, P.D.; Kalil, A.C. What is the efficacy and safety of colistin for the treatment of ventilator-associated pneumonia? A systematic review and meta-regression. Clin. Infect. Dis. 2012, 54, 670-680. [CrossRef] [PubMed]

51. Liang, C.-A.; Lin, Y.-C.; Lu, P.-L.; Chen, H.-C.; Chang, H.-L.; Sheu, C.-C. Antibiotic strategies and clinical outcomes in critically ill patients with pneumonia caused by carbapenem-resistant Acinetobacter baumannii. Clin. Microbiol. Infect. 2018, 24, 908.E1-908.E7. [CrossRef]

52. Bonkat, G.; Bartoletti, R..; Cai, T.; Bruyere, F.; Geerlings, S.E.; Köves, B.; Schubert, S.; F., W.; Mezei, T.; Pilatz, A.; et al. Guidelines on Urological Infections; European Association of Urology: Arnhem, The Netherlands, 2021; pp. 1-66.

53. Babich, T.; Zusman, O.; Elbaz, M.; Ben-Zvi, H.; Paul, M.; Leibovici, L.; Avni, T. Empirical Antibiotic Treatment Does Not Improve Outcomes in Catheter-Associated Urinary Tract Infection: Prospective Cohort Study. Clin. Infect. Dis. 2017, 65, 1799-1805. [CrossRef] [PubMed]

54. Åkerlund, A.; Jonasson, E.; Matuschek, E.; Serrander, L.; Sundqvist, M.; Kahlmeter, G. EUCAST rapid antimicrobial susceptibility testing (RAST) in blood cultures: Validation in 55 European laboratories. J. Antimicrob. Chemother. 2020, 75, 3230-3238. [CrossRef]

55. Van Belkum, A.; Burnham, C.-A.D.; Rossen, J.W.A.; Mallard, F.; Rochas, O.; Dunne, W.M. Innovative and rapid antimicrobial susceptibility testing systems. Nat. Rev. Microbiol. 2020, 18, 299-311. [CrossRef]

56. Avershina, E.; Shapovalova, V.; Shipulin, G. Fighting Antibiotic Resistance in Hospital-Acquired Infections: Current State and Emerging Technologies in Disease Prevention, Diagnostics and Therapy. Front. Microbiol. 2021, 12, 2044. [CrossRef]

57. Ferrer, R.; Martin-Loeches, I.; Phillips, G.; Osborn, T.M.; Townsend, S.; Dellinger, R.P.; Artigas, A.; Schorr, C.; Levy, M.M. Empiric antibiotic treatment reduces mortality in severe sepsis and septic shock from the first hour: Results from a guideline-based performance improvement program. Crit. Care Med. 2014, 42, 1749-1755. [CrossRef]

58. Karaiskos, I.; Lagou, S.; Pontikis, K.; Rapti, V.; Poulakou, G. The "Old" and the "New" Antibiotics for MDR Gram-Negative Pathogens: For Whom, When, and How. Front. Public Health 2019, 7, 151. [CrossRef]

59. Suay-García, B.; Pérez-Gracia, M.T. Present and Future of Carbapenem-resistant Enterobacteriaceae (CRE) Infections. Antibiotics 2019, 8, 122. [CrossRef]

60. Xu, E.; Pérez-Torres, D.; Fragkou, P.C.; Zahar, J.-R.; Koulenti, D. Nosocomial Pneumonia in the Era of Multidrug-Resistance: Updates in Diagnosis and Management. Microorganisms 2021, 9, 534. [CrossRef] [PubMed]

61. Jackson, N.; Czaplewski, L.; Piddock, L.J.V. Discovery and development of new antibacterial drugs: Learning from experience? J. Antimicrob. Chemother. 2018, 73, 1452-1459. [CrossRef] [PubMed]

62. Fritzenwanker, M.; Imirzalioglu, C.; Herold, S.; Wagenlehner, F.M.; Zimmer, K.-P.; Chakraborty, T. Treatment Options for Carbapenem- Resistant Gram-Negative Infections. Dtsch. Arztebl. Int. 2018, 115, 345-352. [CrossRef] [PubMed]

63. Mikhail, S.; Singh, N.B.; Kebriaei, R.; Rice, S.A.; Stamper, K.C.; Castanheira, M.; Rybak, M.J. Evaluation of the Synergy of Ceftazidime-Avibactam in Combination with Meropenem, Amikacin, Aztreonam, Colistin, or Fosfomycin against WellCharacterized Multidrug-Resistant Klebsiella pneumoniae and Pseudomonas aeruginosa. Antimicrob. Agents Chemother. 2019, 63, e00779-19. [CrossRef]

64. Falcone, M.; Daikos, G.L.; Tiseo, G.; Bassoulis, D.; Giordano, C.; Galfo, V.; Leonildi, A.; Tagliaferri, E.; Barnini, S.; Sani, S.; et al. Efficacy of Ceftazidime-avibactam Plus Aztreonam in Patients with Bloodstream Infections Caused by Metallo- $\beta$-lactamaseProducing Enterobacterales. Clin. Infect. Dis. 2021, 72, 1871-1878. [CrossRef]

65. Lewis, R.H.; Sharpe, J.P.; Swanson, J.M.; Fabian, T.C.; Croce, M.A.; Magnotti, L.J. Reinventing the wheel: Impact of prolonged antibiotic exposure on multidrug-resistant ventilator-associated pneumonia in trauma patients. J. Trauma Acute Care Surg. 2018, 85, 256-262. [CrossRef]

66. Magiorakos, A.-P.; Srinivasan, A.; Carey, R.B.; Carmeli, Y.; Falagas, M.E.; Giske, C.G.; Harbarth, S.; Hindler, J.F.; Kahlmeter, G.; Olsson-Liljequist, B.; et al. Multidrug-resistant, extensively drug-resistant and pandrug-resistant bacteria: An international expert proposal for interim standard definitions for acquired resistance. Clin. Microbiol. Infect. 2012, 18, 268-281. [CrossRef] [PubMed] 
67. European Centre for Disease Prevention and Control. Surveillance of Healthcare-Associated Infections and Prevention Indicators in European Intensive Care Units; ECDC: Stockholm, Sweden, 2017.

68. European Centre for Disease Prevention and Control. Point Prevalence Survey of Healthcare-Associated Infections and Antimicrobial Use in European Acute Care Hospitals_Protocol Version 5.3; ECDC: Stockholm, Sweden, 2016.

69. The European Committee on Antimicrobial Susceptibility Testing. Breakpoint Tables for Interpretation of MICs and Zone Diameters, Version 10.0. 2020. Available online: http:/ / www.eucast.org (accessed on 15 April 2021). 